\title{
Effects of the COVID-19 on Air Quality: Human Mobility, Spillover Effects, and City Connections
}

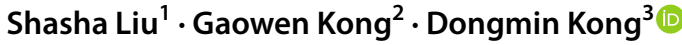

Accepted: 14 July 2020 / Published online: 4 August 2020

(c) Springer Nature B.V. 2020

\begin{abstract}
We quantify the causal effects of the coronavirus disease 2019 (COVID-19) on air quality in the context of China. Using the lockdowns in different cities as exogenous shocks, our difference-in-differences estimations show that lockdown policies significantly reduced air pollution by $12 \%$ on average. Based on the first lockdown city, Wuhan, we present three underlying mechanisms driving our findings: anticipatory effects, spillover effects, and a city's level of connection with Wuhan. Our findings are more pronounced in cities whose population was more willing to self-isolate or more susceptible to anxiety, or whose government faces less pressure to stimulate economic growth. Overall, this study contributes to the literature by evaluating the unintended consequences of the COVID-19 outbreak for air quality, and provides timely policy implications for policymakers.
\end{abstract}

Keywords COVID-19 $\cdot$ Air quality $\cdot$ Human mobility $\cdot$ Spillover $\cdot$ Connections

JEL Classification Q53 - Q56 · F64 · O13

\section{Introduction}

The coronavirus disease 2019 (COVID-19) crisis was caused by a viral pandemic that abruptly and severely constricted human mobility and economic activity. Governments worldwide have increasingly implemented strict public health measures in response to the outbreak, such as social distancing and even complete lockdowns.

Dongmin Kong

kongdm@hust.edu.cn

Shasha Liu

sarahliu@jnu.edu.cn

Gaowen Kong

konggaowen@gmail.com

1 School of Management, Jinan University, Guangzhou, China

2 School of Management, Guangzhou University, Guangzhou, China

3 School of Finance, Zhongnan University of Economics and Law, Wuhan, China 
The shock of the COVID-19 crisis gives us a unique opportunity to investigate the causal effect of social distancing or a pause in human mobility and economic activities, which is generally impossible, on air quality. In this paper, we exploit the exogenous shock of COVID-19 and use a variety of high-quality data sets to study the causal effect of an unprecedented change in human mobility and economic activity on air pollution in the Chinese context.

We focus on China for two reasons. First, China suffers from severe air pollution (Chen et al. 2018; Freeman et al. 2019; Heyes and Zhu 2019; Shi and Xu 2018; Wang et al. 2018). Second, China offers a good setting for assessing the economic impact of COVID-19. It was the first country in the world to experience a large-scale outbreak, starting in January 2020, which means that there has been a sufficiently long post-outbreak period to ensure we have the statistical power for credible estimation.

We use various difference-in-differences (DID) estimation strategies to disentangle the effect of COVID-19 on AQI from other confounding effects (Fang et al. 2020). In particular, we introduce two alternative specifications of the treatment group to ensure the reliability of our estimation. In both specifications, we present strong evidence that lockdown policies significantly reduced air pollution. In our estimation, lockdown policies designed to suppress the spread of COVID-19 in China decreased air pollution by $12 \%$ on average. ${ }^{1}$

We then check the robustness of our findings. First, we verify the identifying assumption associated with our baseline DID specification; that is, we assume that the change in air pollution in the treatment group would have followed the same trend as that in the control group if no lockdown policies had been issued. Second, we introduce a regression discontinuity design (RDD) to examine whether our findings are sensitive to the window width before and after the policy period. In both robustness checks, we got highly consistent results.

To explore the mechanism underlying our findings, we conduct three tests examining the anticipatory effects, spillover effects, and cities' connection to Wuhan. First, we present evidence that the prior information leakage about lockdowns distorted human anticipation and behaviors, induced a significant increase in air pollution. Second, the Wuhan lockdown had significant spillover effects on other cities in terms of increased air quality, due to the effect on human mobility. Third, we construct a variable Connections to capture a city's level of connection to Wuhan based on real-time between-city population movements data from Baidu. Our results show that connection with Wuhan significantly strengthened the effect of lockdown policies and the spillover effect of the Wuhan lockdown.

Finally, we examine the heterogeneous effects of public willingness to self-isolate, public panic, or government GDP incentives on our baseline findings, and find that the effect of lockdown policies is higher in cities that have more people willing to self-isolate, more public panic, or governments under less pressure to stimulate economic growth.

Our study is related to, but differs from, a recent paper (He et al. 2020) that also examines the effect of the COVID-19 pandemic on air pollution. First, we use two alternative settings to conduct DID estimation, to ensure that our findings are solid. Second, our rich

\footnotetext{
1 It is worth noting that air pollution levels are back to normal in many Chinese cities (https://www.reute rs.com/article/us-health-coronavirus-china-pollution/china-sees-post-lockdown-rise-in-air-pollution-study -idUSKBN22U09F). Although the impact of COVID-19 on pollutions is temporary, this study focusses on the evaluation of the first-order effect of COVID-19 shock on air quality and identification of the underlying mechanisms behind our findings. In effect, the fact that air pollution levels are back to normal further validate our findings given that the increase in air pollution is associated with the relax of lockdown and resumption of a large part of business activities in China.
} 
data set based on population movements data from Baidu allows us to explore the moderating effect of human mobility and a city's connection to Wuhan behind our baseline results. Third, based on a mechanism analysis, we explore how the anticipations of lockdown policies moderates the effect of these policies and the spillover effect of the Wuhan lockdown on other cities' air quality. Finally, we analyze cross-sectional heterogeneity based on willingness to self-isolate, public panic, or government's GDP incentives, which enriches our understanding of the effects of COVID-19 on air quality.

We contribute to the literature in two ways. First, we add to the rapidly growing literature about the economic consequences of the COVID-19 pandemic by showing its sizeable effects on air quality. We thus complement existing studies of consumption, labor markets, capital market violability, human mobility, and firm operations (Baker et al. 2020; Bartik et al. 2020; Chen et al. 2020; Ding et al. 2020; Hassan et al. 2020; Dingel and Neiman 2020; Fang et al. 2020; Coibion et al. 2020). We also complement policy evaluation of the unintended consequences of different policies for air quality (Barron and Torero 2017; Fu and Gu 2017; Lalive et al. 2018; Zhang et al. 2017). Second, by evaluating the determinants of air quality in China, this study complements the emerging literature on its causes and consequences (Chen et al. 2018; Freeman et al. 2019; Heyes and Zhu 2019; Wang et al. 2018), thereby offering timely implications for policymakers. In addition, we present strong evidence that human mobility, economic activities, economic connection, willingness to self-isolate, public panic, and GDP growth incentives are important driving forces of air pollution. Such findings could be taken as a benchmark for regulators aiming to improve environmental protection and reduce toxic emissions when the economy recovers from COVID-19.

The remainder of this paper is organized as follows. Section 2 describes the data set and empirical strategy. Section 3 presents the baseline results. Section 4 explores the underlying mechanisms and cross-sectional heterogeneity. Section 5 concludes the paper.

\section{Data and Empirical Strategy}

\subsection{Data and Descriptive Statistics}

The two main data sets that we use are daily air quality index (AQI) data and daily weather reports for major cities in China.

\subsubsection{AQI Data}

To describe the air pollution level in each city, we obtain AQI data from the website of the Ministry of Ecology and Environment of the People's Republic of China (http://www.zhb. gov.cn/). The website provides daily information on the AQI, air quality class, and primary pollutants in 400 cities in China. According to the standard of the Ministry of Ecology and Environment of the People's Republic of China, the AQI is based on the level of six atmospheric pollutants: sulfur dioxide $\left(\mathrm{SO}_{2}\right), \mathrm{NO}_{2}$, suspended particulates smaller than $10 \mu \mathrm{m}$ in aerodynamic diameter $\left(P M_{10}\right)$, suspended particulates smaller than $2.5 \mu \mathrm{m}$ in aerodynamic diameter $\left(P M_{2.5}\right)$, carbon monoxide $(C O)$, and ozone $\left(O_{3}\right)$. Based on the concentrations of each pollutant, an Individual Air Quality Index (IAQI) score is assigned, and the final AQI is the highest of these six scores. A higher $A Q I$ means more atmospheric pollutants in air and a higher level of air pollutions. 


\subsubsection{Weather Data}

To measure the weather conditions, we obtain data on the maximum wind speed, precipitation, average humidity, and average temperature at each station from the China Meteorological Administration (CMA) website. We then define city level weather conditions as the average of stations within the corresponding city.

\subsection{Model Specifications}

According to some reports, the COVID-19 virus is so dangerous that the median time between the onset of symptoms and death may be as little as 10 days. Moreover, COVID19 can be transmitted while the carrier is still asymptomatic. These characteristics make COVID-19 a huge threat to healthcare capacity. To suppress the spread of COVID-19, China imposed an unprecedented extreme intervention by placing Hubei province and especially Wuhan city on lockdown. Wuhan was placed on lockdown at 10 a.m., January 20, 2020, and other cities in Hubei were locked down several days later. As COVID-19 spread, more and more cities issued different lockdown policies. According to Fang et al. (2020), 80 cities in 22 provinces issued different levels of lockdown policies before February 20, 2020.

Based on this setting, we use several DID estimation strategies by comparing different treatment and control groups to identify the impact of lockdown policies on air quality. The DID specification can be described as follows:

$$
\ln (A Q I)_{i, t}=\alpha_{i}+\beta_{1} \text { Treat }_{i, t} * \text { Post }_{i, t}+W_{i, t}+X_{i, t}+\epsilon_{i, t}
$$

where $i$ denotes the city and $t$ denotes the day. The dependent variable $\ln (A Q I)_{i, t}$ is a measure of air pollution in city $i$ on day $t$, which equals the logarithm of the air quality index. The key variable of our DID design is Treat $_{i, t} *$ Post $_{i, t}$. Considering that within different specific designs we use different control groups, and the definitions of Treat $_{i, t}$ and Post $_{i, t}$ thus vary between research designs, we are explicit about their definitions below. According to $\mathrm{Fu}$ and $\mathrm{Gu}$ (2017), weather conditions influence emissions and air quality. For example, precipitation and wind speed are key meteorological variables influencing near-surface particulate matter within cities (Jones et al. 2010), and cloudy, cool, rainy, or windy days hinder the formulation of ozone. We also control for daily weather variables $W_{i, t}$, a vector of daily weather for city $i$ on day $t$, including maximum wind speed, precipitation, average humidity, and average temperature, to eliminate the impact of weather conditions. Lastly, we control for several fixed effects. We control for city fixed effect $\alpha_{i}$ to eliminate the impact of unobserved, time-unvarying city attributes on air quality. We control for the date fixed effect $X_{i, t}$ to eliminate the impact of time-varying attributes on air quality, including a weekend dummy, month dummies, year 2020 dummy, and Spring Festival Holiday dummy.

Model (1) has the special cases in our different research designs. First, following the DID strategy, we can estimate Model (1) by studying the different effects of the lockdown policy on a treatment group versus a control group. Second, if we choose a small window before and after the lockdown policy, Model (1) can be estimated following the regression discontinuity design (RDD) method, because such an estimation can show whether the trend in air quality has a "jump" during and after the policy period (Fu and Gu 2017). Following Gelman and Imbens (2019), who provide three reasons why high-order polynomials 
Table 1 Summary statistics

\begin{tabular}{|c|c|c|c|c|c|}
\hline & Mean & SD & $\mathrm{P} 25$ & Median & P75 \\
\hline \multicolumn{6}{|c|}{ Panel A: all cities } \\
\hline AQI & 4.172 & 0.586 & 3.747 & 3.747 & 4.566 \\
\hline PM2.5 & 3.681 & 0.752 & 3.161 & 3.161 & 4.217 \\
\hline $\mathrm{NO}_{2}$ & 3.122 & 0.624 & 2.680 & 2.680 & 3.588 \\
\hline Wind speed & 4.515 & 2.401 & 3.000 & 3.000 & 6.000 \\
\hline Precipitation & 1.115 & 3.760 & 0.000 & 0.000 & 0.100 \\
\hline Humidity & 0.659 & 0.198 & 0.514 & 0.514 & 0.814 \\
\hline Temperature & 3.433 & 9.633 & -2.840 & -2.840 & 10.014 \\
\hline Observations & 17,160 & & & & \\
\hline \multicolumn{6}{|c|}{ Panel B: pre-lockdown of locked cities } \\
\hline AQI & 4.185 & 0.566 & 3.765 & 3.765 & 4.651 \\
\hline PM2.5 & 3.800 & 0.688 & 3.345 & 3.345 & 4.356 \\
\hline $\mathrm{NO}_{2}$ & 2.914 & 0.548 & 2.546 & 2.546 & 3.269 \\
\hline \multicolumn{6}{|c|}{ Panel C: post-lockdown of locked cities } \\
\hline AQI & 3.985 & 0.570 & 3.528 & 3.528 & 4.420 \\
\hline PM2.5 & 3.492 & 0.745 & 2.974 & 2.974 & 4.058 \\
\hline $\mathrm{NO}_{2}$ & 2.656 & 0.536 & 2.337 & 2.337 & 2.996 \\
\hline
\end{tabular}

This table presents the descriptive statistics of our main variables. Panel A reports the summary statistics of all cities in 2020 and 2019. Then we report the air quality or air pollution before and after the official lockdown issue of locked cities. Panel B reports the statistics before the official lockdown. Panel $\mathrm{C}$ reports the statistics after the official lockdown

should not be used in RDD, we add a linear or quadratic polynomial term $f(t)$ in our RDD estimation. The RDD specification can be described as follows:

$$
\ln (A Q I)_{i, t}=\alpha_{i}+\beta_{1} \text { Treat }_{i, t} * \text { Post }_{i, t}+W_{i, t}+X_{i, t}+f(t)+\epsilon_{i, t}
$$

where $i$ and $t$ denote the city and day respectively, $f(t)$ denotes a flexible polynomial time trend term controlling for unobserved confounding factors that may affect daily air quality.

\section{Estimation Result}

\subsection{Summary Statistics}

We present the summary statistics of the key variables in Table 1 . We winsorize all of the continuous variables at the 1 st and 99th percentiles to alleviate the concern that our results may be driven by outliers. Panel A of Table 1 presents the summary statistics for the full sample. The dependent variable $\ln (A Q I)$ has a mean of 4.172 with a variance of 0.586 . This means that during our sample period, the average air quality of China could be categorized as "good" according to the standard of the Ministry of Ecology and Environment of the People's Republic of China. However, the 75th percentile of $\ln (A Q I)$ is 4.566 , which means that nearly a quarter of city-days should still be categorized as "lightly polluted" or worse. 
Panel B presents the air quality within the pre-lockdown period of cities that implemented lockdown interventions and Panel $\mathrm{C}$ reports the air quality for the post-lockdown period of these cities as. Whether it is measured by $\ln (A Q I), \ln \left(P M_{2.5}\right)$, or $\ln \left(N O_{2}\right)$, the air quality after lockdown is much better than the air quality before lockdown, suggesting a reduction in air pollution due to the lockdown policy. ${ }^{2}$

\subsection{Baseline Results}

In this section, we estimate Model (1) to identify the impact of lockdown policies on air pollution. Here, we implement two DID strategies that differ in the estimation sample, and the definition of the variable Treat.

First, we use the sample of 80 cities that issued lockdown policies during the coronavirus outbreak. Following Fang et al. (2020), we compare the change in air quality in these cities in 2020 to the same cities in the matching lunar calendar period in 2019. Under this setting, Treat $t_{i, t}$ takes the value of 1 for the 2020 data of city $i$, and 0 for the 2019 data. Post $_{i, t}$ is a dummy variable that takes the value of 1 for the sample period after city $i$ issued a lockdown policy in 2020, or after the same lunar calendar date in 2019, and 0 otherwise.

Second, we use the sample of 2020 data for 80 locked-down cities and 284 cities that were never locked down during the coronavirus outbreak. Under this setting, Treat $_{i, t}$ takes the value of 1 if city $i$ issued any lockdown policy in 2020, and 0 otherwise. Thus, the control group consists of 284 cities that were not subject to lockdowns. ${ }^{3}$ Post $_{i, t}$ takes the value of 1 for the sample period after city $i$ issued a lockdown policy, and 0 otherwise.

We interpret the coefficient of Treat $_{i, t} *$ Post $_{i, t}$ as the impact of lockdowns on air quality or pollution in both of the above strategies. Panel A of Table 2 presents the results.

The dependent variable of Panel A is the logarithm of AQI. Columns (1) and (2) are results of the first strategy and columns (3) and (4) are results of the second strategy. The coefficient of Treat $*$ Post in column (1) is significantly negative and shows that in 2020 the AQI decreased by $13.5 \%$ during the lockdown period compared with the same lunar calendar period in 2019. Column (2) presents the results of Model (1) with a vector of weather variables and a vector of fixed effects. The coefficient of Treat * Post is significantly negative and is larger in magnitude. Columns (3) and (4) present consistent results.

The AQI level is based on the levels of six atmospheric pollutants. Based on the concentrations of each pollutant, an individual Individual Air Quality Index (IAQI) score is assigned to each and the final $A Q I$ is the highest of these six scores. Therefore, we conduct two robustness checks by investigating the impact of lockdown policies on the IAQI of $P M_{2.5}$ and $\mathrm{NO}_{2}$. we define $\ln \left(\mathrm{PM}_{2.5}\right)$ and $\ln \left(\mathrm{NO}_{2}\right)$ as the logarithms of the IAQI s of $P M_{2.5}$ and $\mathrm{NO}_{2}$, and regress them as Model (1). Panel $\mathrm{B}$ and $\mathrm{C}$ of Table 2 report the regression results.

Panel B of Table 2 presents the results of $\ln \left(P M_{2.5}\right)$, and shows that the coefficients of Treat $*$ Post are all significantly negative and suggest that the level of $\mathrm{PM}_{2.5}$ decreased by

\footnotetext{
2 We compare the difference of other control variables, and find no significant difference after controlling the fixed effects. For brevity, related results are not presented but available upon request.

${ }^{3}$ One concern here is that the strong supply-chain effects of virus may potentially bias our estimated results. Specifically, cities that were not subject to lockdowns still may be affected by the virus through the decreasing population mobility or labor demand of locked cities. Given the data limitation, we leave this issue in the future study.
} 
Table 2 Baseline results

\begin{tabular}{|c|c|c|c|c|}
\hline \multirow{4}{*}{$\begin{array}{l}\text { Treatment group } \\
\text { Control group }\end{array}$} & \multicolumn{4}{|l|}{ AQI } \\
\hline & \multirow{2}{*}{\multicolumn{2}{|c|}{$\frac{\text { Locked cities } 2020}{\text { Locked cities } 2019}$}} & \multirow{2}{*}{\multicolumn{2}{|c|}{$\frac{\text { Locked cities } 2020}{\text { Unlocked cities } 2020}$}} \\
\hline & & & & \\
\hline & (1) & (2) & (3) & (4) \\
\hline \multicolumn{5}{|l|}{ Panel A: AQI } \\
\hline Treat $*$ Post & $\begin{array}{l}-0.135^{* * *} \\
(0.020)\end{array}$ & $\begin{array}{l}-0.159 * * * \\
(0.019)\end{array}$ & $\begin{array}{l}-0.083^{* * *} \\
(0.016)\end{array}$ & $\begin{array}{l}-0.106^{* * *} \\
(0.015)\end{array}$ \\
\hline Weather & No & $\mathrm{Y}$ & No & $\mathrm{Y}$ \\
\hline Fixed effects & $\mathrm{Y}$ & $\mathrm{Y}$ & $\mathrm{Y}$ & $\mathrm{Y}$ \\
\hline Constant & $\begin{array}{l}4.252 * * * \\
(0.007)\end{array}$ & $\begin{array}{l}3.864 * * * \\
(0.035)\end{array}$ & $\begin{array}{l}4.118 * * * \\
(0.004)\end{array}$ & $\begin{array}{l}3.843 * * * \\
(0.024)\end{array}$ \\
\hline Observations & 6602 & 6602 & 13,860 & 13,858 \\
\hline $\mathrm{R}^{2}$ & 0.453 & 0.527 & 0.525 & 0.580 \\
\hline \multicolumn{5}{|l|}{ Panel B: PM2.5 } \\
\hline Treat $*$ Post & $\begin{array}{l}-0.247 * * * \\
(0.025)\end{array}$ & $\begin{array}{l}-0.241^{* * *} \\
(0.024)\end{array}$ & $\begin{array}{l}-0.114 * * * \\
(0.020)\end{array}$ & $\begin{array}{l}-0.140^{* * * *} \\
(0.019)\end{array}$ \\
\hline Weather & No & Yes & No & Yes \\
\hline Fixed effects & Yes & Yes & Yes & Yes \\
\hline Constant & $\begin{array}{l}3.818 * * * \\
(0.009)\end{array}$ & $\begin{array}{l}3.257 * * * \\
(0.044)\end{array}$ & $\begin{array}{l}3.661 * * * \\
(0.005)\end{array}$ & $\begin{array}{l}3.199 * * * \\
(0.029)\end{array}$ \\
\hline Observations & 6602 & 6602 & 13,860 & 13,858 \\
\hline $\mathrm{R}^{2}$ & 0.449 & 0.545 & 0.550 & 0.618 \\
\hline \multicolumn{5}{|l|}{ Panel $\mathrm{C}: \mathrm{NO}_{2}$} \\
\hline Treat $*$ After & $\begin{array}{l}-0.359 * * * \\
(0.016)\end{array}$ & $\begin{array}{l}-0.382^{* * * *} \\
(0.016)\end{array}$ & $\begin{array}{l}-0.140^{* * * *} \\
(0.014)\end{array}$ & $\begin{array}{l}-0.160 \text { *** } \\
(0.013)\end{array}$ \\
\hline Weather & No & Yes & No & Yes \\
\hline Fixed effects & Yes & Yes & Yes & Yes \\
\hline Constant & $\begin{array}{l}3.321 * * * \\
(0.006)\end{array}$ & $\begin{array}{l}3.104 * * * \\
(0.029)\end{array}$ & $\begin{array}{l}3.036 * * * \\
(0.003)\end{array}$ & $\begin{array}{l}2.804 * * * \\
(0.019)\end{array}$ \\
\hline Observations & 6602 & 6602 & 13,860 & 13,858 \\
\hline $\mathrm{R}^{2}$ & 0.691 & 0.736 & 0.709 & 0.751 \\
\hline
\end{tabular}

This table reports the impact of the lockdown policy on air pollution. Column (1) and (2) compare the locked cities in 2020 to itself in 2019, and column (3) and (4) compare the locked cities in 2020 to unlocked cities in 2020. Besides, column (1) and (3) present the result with the fixed effects, and column (2) and (4) present the regression with both the weather conditions and fixed effects. The dependent variable is $A Q I, P M 2.5$ and $\mathrm{NO}_{2}$ in panel A, B and C, respectively. The key independent variable is Treat $*$ Post

Significance at $10 \%, 5 \%$, and $1 \%$ levels was indicated by ***, and ***, respectively 
$11 \%$ or $24 \%$ during the lockdown period. Panel C of Table 2 presents the result of $\ln \left(\mathrm{NO}_{2}\right)$, and shows consistent results. ${ }^{4}$

In summary, we find a significant and robust relationship between lockdown policies and air pollution with different control groups. The lockdown policies intended to suppress the spread of COVID-19 in China significantly decreased air pollution by $12 \%$ on average. ${ }^{5}$

\subsection{Robustness Checks}

First, the identifying assumption associated with our baseline DID estimation specification is that the change in $A Q I$ in the treatment group would have followed the same trend as that in the control group if no lockdown policies had been issued. Thus, we examine the dynamic effect in the regression framework to address possible concerns about our identifying assumption. Specifically, we create a series of time dummy variables Post ${ }_{i, t}^{\eta}$ by modifying the official issue date of lockdown policies within 1 week around the real date, and interact each of them with our treatment variable using the following regression:

$$
\ln (A Q I)_{i, t}=\alpha_{i}+\sum_{\mathrm{n}=-4}^{\mathrm{n}=3} \beta_{n} \text { Treat }_{i, t} * \text { Post }_{i, t}^{n}+W_{i, t}+X_{i, t}+\epsilon_{i, t}
$$

where Post $_{i, t}^{n}$ is a dummy variable that takes the value of 1 for $n$ days after (before) city $i$ issues a lockdown policy in 2020, or the same lunar calendar date in 2019, and 0 otherwise. A total of seven dummies are accumulated, spanning a week around the official issue date. In this regression, we are particularly interested in the difference in the coefficients for all of the interaction terms, which we plot in Fig. 1.

Figure 1 presents the difference in the interaction terms' coefficients. The left (right) graph shows the distribution of interaction terms' coefficients when we compare lockeddown cities in 2020 to the same cities in 2019 (locked-down cities to unlocked-down cities in 2020). Both these plots show that during the pre-lockdown days the coefficients are clearly insignificantly different from zero, while the coefficients during the post-lockdown days are clearly significantly negative. This figure demonstrates that the impact of lockdown policies on air pollution was not induced by time trends.

Next, to check whether the preceding results are sensitive to the window width before and after the policy period, we use the RDD method with local linear or quadratic polynomial time terms to estimate the "jump" in air pollution before and after the lockdown policies within a narrow window. Specifically, we regress $\ln (A Q I)$ as Model (2), which adds a linear or quadratic time trend before and after the issue of each city's lockdown policies. To perfectly capture the "jump" of AQI, we only focus on observations 7 days around the issue of lockdown policies. Table 3 reports the regression results.

Column (1) (2) and (3) present the results with no, linear and quadratic time trend respectively. All coefficients of Treat $*$ Post are significantly negative, suggesting that air pollution did "jump" with the issuing of lockdown policies, which is consistent with Table 2.

\footnotetext{
${ }^{4}$ We also construct the control group more comparable with the treatment group by focusing on the cities adjoining boundary to Hubei province, or prefecture-level cities only, and find our conclusions are robust. For brevity, related results are not presented but available upon request.

5 Given that the national policies with COVID-19, such as the school and firm shutdown, could also affect cities that were not subject to lockdown, the pure effect of lockdown might be underestimated here. As our findings is quite solid and strong, we believe that after the adjustment of the potential underestimation, our results might be more significant than the current results.
} 

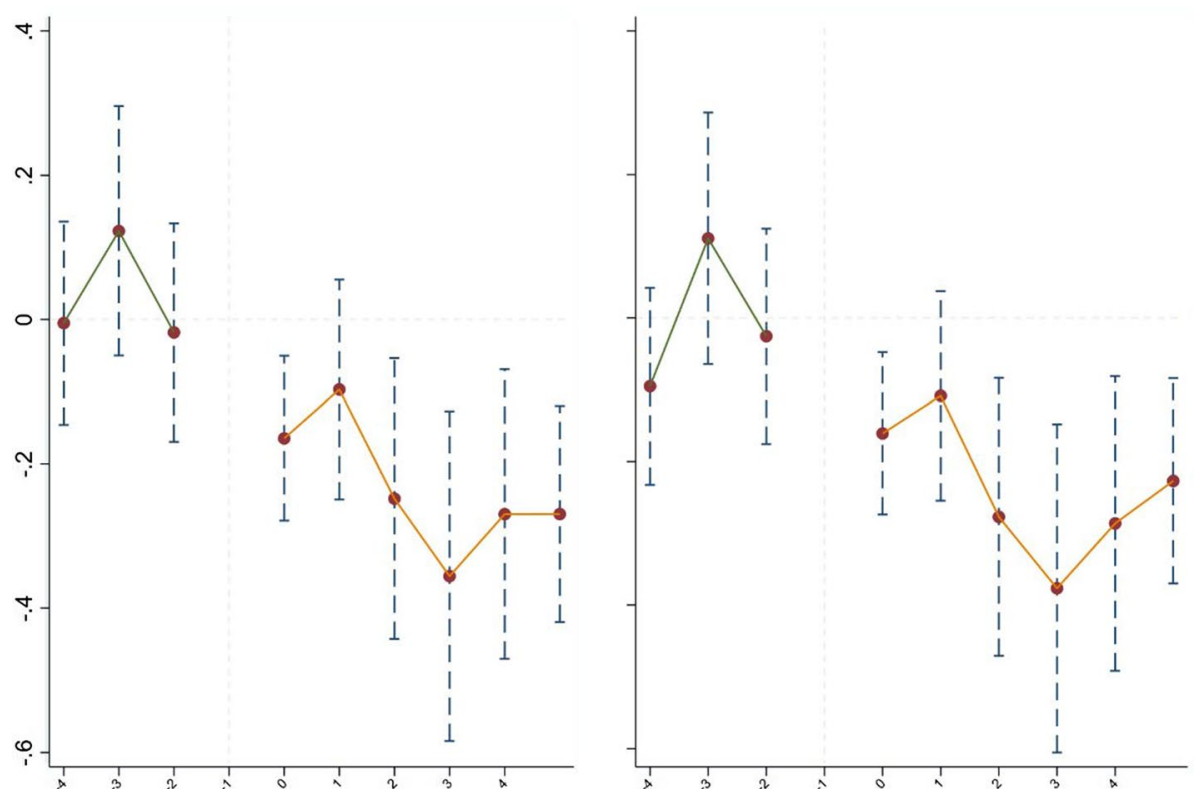

Fig. 1 Dynamic DID. Note This figure plots the difference of interaction terms' coefficients between the period before and after the official lockdown day under a continuous treatment variable. The solid line shows the estimated coefficients over time. In each day, the dashed line surrounding the coefficient is $95 \%$ confidence intervals of it

\section{Potential Mechanisms and Heterogenous Effects}

\subsection{Anticipatory Effects}

Although the lockdown had a considerable impact on air pollution and significant effects on $A Q I$ and IAQI, it may also have increased air pollution. Fang et al. (2020) show that a panic effect in reaction to the outbreak could significantly impact human behaviors. For example, before the government officially confirmed the lockdown, rumors that Wuhan would be locked down spread on the Internet. For example, the Baidu Search Index for "Wuhan lockdown" was 0 before January 20, increased to 15,649 and 21,905 in the next 2 days. Such information leakage has a significant impact on human behaviors and can cause major social chaos. It can also have had a significant effect on air pollution, such as increasing public and private transportation, or abnormal information seeking of people who anticipated the lockdown policy.

To investigate the impact of anticipated future lockdowns, we first provide visual evidence in Fig. 2 by applying the RDD method and estimating the effect of the lockdown policy on air pollution in Wuhan, the first city to be locked down in response to the COVID-19 outbreak.

Figure 2 shows the quadratic trend of $A Q I$ within three periods: from 11 to 3 days before the issue of the lockdown policy, from 3 days before to the issue day, and from the issue day to 7 days after. The left graph presents the trend in 2020 and suggests that the air pollution of Wuhan "jumps" twice in our sample. Due to anticipatory of lockdown, air pollution increased greatly from 3 days before. After Wuhan was officially placed on lockdown, air pollution decreased much more, and even lower than the level within the period 11 days 
Table 3 RDD estimation

\begin{tabular}{|c|c|c|c|}
\hline & \multicolumn{3}{|l|}{ AQI } \\
\hline & (1) & (2) & (3) \\
\hline Treat * Post & $\begin{array}{l}-0.174 * * * \\
(0.031)\end{array}$ & $\begin{array}{l}-0.112 * * \\
(0.057)\end{array}$ & $\begin{array}{l}-0.120 * * \\
(0.057)\end{array}$ \\
\hline Wind speed & $\begin{array}{l}-0.011 \\
(0.009)\end{array}$ & $\begin{array}{l}-0.011 \\
(0.009)\end{array}$ & $\begin{array}{l}-0.012 \\
(0.009)\end{array}$ \\
\hline Precipitation & $\begin{array}{l}-0.013^{* *} \\
(0.006)\end{array}$ & $\begin{array}{l}-0.013 * * \\
(0.006)\end{array}$ & $\begin{array}{l}-0.013 * * \\
(0.006)\end{array}$ \\
\hline Humidity & $\begin{array}{l}0.555 * * * \\
(0.141)\end{array}$ & $\begin{array}{l}0.539 * * * \\
(0.142)\end{array}$ & $\begin{array}{l}0.525 * * * \\
(0.143)\end{array}$ \\
\hline Temperature & $\begin{array}{l}0.048 * * * \\
(0.005)\end{array}$ & $\begin{array}{l}0.050 * * * \\
(0.005)\end{array}$ & $\begin{array}{l}0.050 * * * \\
(0.005)\end{array}$ \\
\hline Time trend & No & 1st order & 2nd order \\
\hline Fixed effects & Yes & Yes & Yes \\
\hline Constant & $\begin{array}{l}3.706 * * * \\
(0.116)\end{array}$ & $\begin{array}{l}3.678 * * * \\
(0.118)\end{array}$ & $\begin{array}{l}3.696^{* * * *} \\
(0.120)\end{array}$ \\
\hline Observations & 825 & 825 & 825 \\
\hline $\mathrm{R}^{2}$ & 0.590 & 0.591 & 0.591 \\
\hline
\end{tabular}

This table reports the impact of the lockdown policy on air pollution within a small window of locked cities. Column (1) presents the result of Model (1) but focusing on observations within 7 days before and after the issues of intervention policies. Column (2) and (3) presents the results of RDD strategy by adding a linear or quadratic time trend separately. The dependent variable is $A Q I$. The key independent variable is Treat $*$ Post

Significance at $10 \%, 5 \%$, and $1 \%$ levels was indicated by *, **, and ***, respectively

before. The right graph of Fig. 2 presents that there is no similar pattern in 2019. Figure 2 suggests that although the lockdown policy considerably decreased air pollution during the lockdown period, the anticipatory effects induced a significant increase of air pollution before the official issue of the lockdown policy, due to information leakage.

Next, we provide empirical evidence of the "anticipatory effects" of lockdown policies in terms of air pollution. We include a pre-lockdown period indicator Before ${ }_{i, t}$, which is a dummy variable and takes the value of 1 for the period from 3 days before the unprecedented announcement of a lockdown policy in city $i$, and 0 otherwise. Before ${ }_{i, t}$ allows us to capture the anticipatory effects of lockdown policies. We re-estimate the impact of lockdown policies on air pollution using city-level data and the following DID specifications:

$$
\ln (A Q I)_{i, t}=\alpha_{i}+\beta_{2} \text { Treat }_{i, t} * \text { Before }_{i, t}+\beta_{2} \text { Treat }_{i, t} * \text { Post }_{i, t}+W_{i, t}+X_{i, t}+\epsilon_{i, t}
$$

where $i$ denotes the city and $t$ denotes the day. The key variables here are Treat $_{i, t} *$ Before $_{i, t}$ and Treat $_{i, t} *$ Post $_{i, t}$ : the former captures the anticipatory effects of lockdown policies and the latter captures the normal effect of lockdown policies. Table 4 reports the regression results.

The coefficient of Treat $*$ Before is significantly positive, which suggests that air pollution increased by $28 \%$ during the period from 3 days before to the official announcement date. We interpret this as the anticipatory effects of leaked information about lockdown 

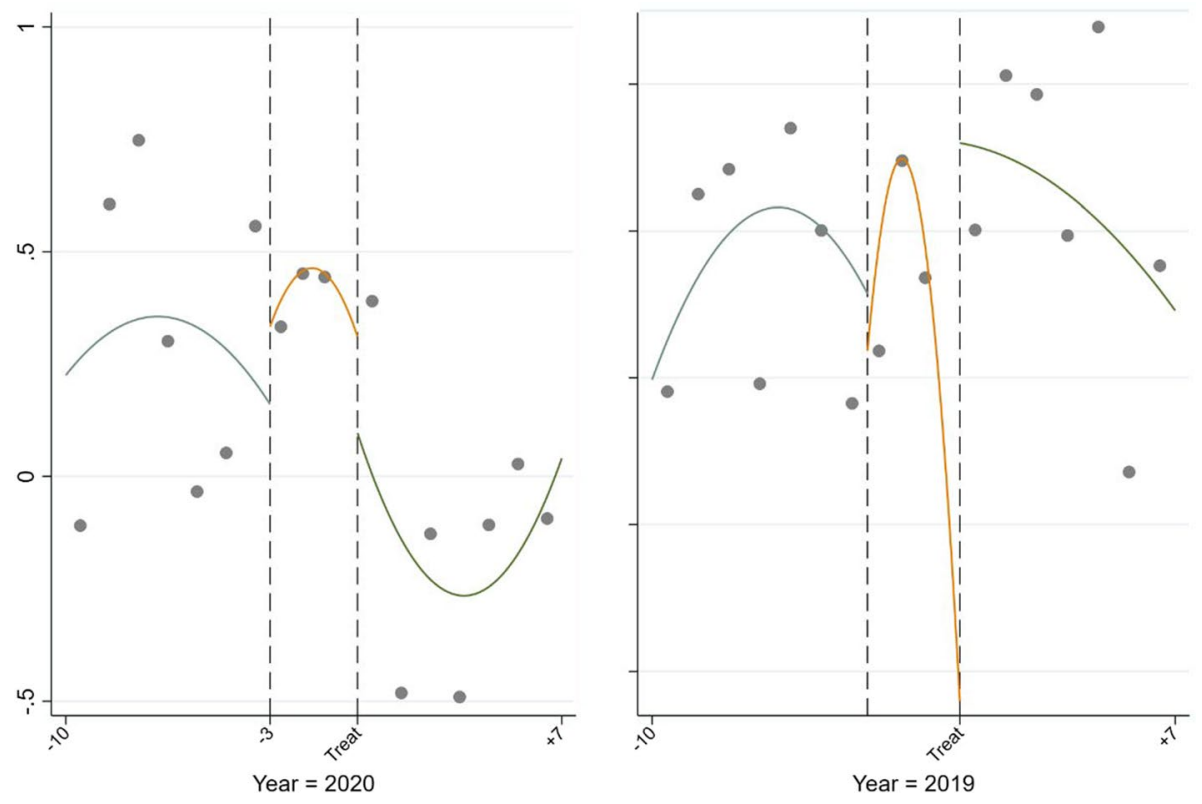

Fig. 2 AQI of Wuhan. Note This figure plots the distributions of AQI of Wuhan city against date. The left and right graphs present the result in 2020 or 2019 around the lunar calendar date of official locked down day, respectively. The lunar calendar date of official locked down day of cities in 2020 is normalized to 0

Table 4 Anticipatory effects

\begin{tabular}{|c|c|c|c|c|}
\hline \multirow{4}{*}{$\begin{array}{l}\text { Treatment group } \\
\text { Control group }\end{array}$} & \multicolumn{4}{|l|}{ AQI } \\
\hline & \multirow{2}{*}{\multicolumn{2}{|c|}{$\frac{\text { Limited cities } 2020}{\text { Limited cities } 2019}$}} & \multirow{2}{*}{\multicolumn{2}{|c|}{$\frac{\text { Limited cities } 2020}{\text { Normal cities } 2020}$}} \\
\hline & & & & \\
\hline & (1) & (2) & (3) & (4) \\
\hline Treat*Before & $\begin{array}{l}0.281 * * * \\
(0.066)\end{array}$ & $\begin{array}{l}0.261 * * * \\
(0.064)\end{array}$ & $\begin{array}{l}0.094 * * * \\
(0.035)\end{array}$ & $\begin{array}{l}0.074 * * \\
(0.033)\end{array}$ \\
\hline Treat * Post & $\begin{array}{l}-0.115^{* * * *} \\
(0.037)\end{array}$ & $\begin{array}{l}-0.160^{* * *} \\
(0.037)\end{array}$ & $\begin{array}{l}-0.081^{* * *} \\
(0.017)\end{array}$ & $\begin{array}{l}-0.107 * * * \\
(0.016)\end{array}$ \\
\hline Weather & No & Yes & No & Yes \\
\hline Fixed effects & Yes & Yes & Yes & Yes \\
\hline Constant & $\begin{array}{l}4.252^{* * * *} \\
(0.007)\end{array}$ & $\begin{array}{l}3.864 * * * \\
(0.035)\end{array}$ & $\begin{array}{l}4.118^{* * * *} \\
(0.004)\end{array}$ & $\begin{array}{l}3.843 * * * \\
(0.024)\end{array}$ \\
\hline Observations & 6602 & 6602 & 13,860 & 13,858 \\
\hline $\mathrm{R}^{2}$ & 0.453 & 0.527 & 0.525 & 0.580 \\
\hline
\end{tabular}

This table reports the impact of the lockdown policy on air pollution. Column (1) and (2) compare the locked cities in 2020 to itself in 2019, and column (3) and (4) compare the locked cities in 2020 to unlocked cities in 2020. Besides, column (1) and (3) present the result with the fixed effects, and column (2) and (4) present the regression with both the weather conditions and fixed effects. The dependent variable is $A Q I$. The key independent variable is Treat $*$ Before

Significance at $10 \%, 5 \%$, and $1 \%$ levels was indicated by *,**, and ***, respectively 
policies. Columns (2) to (4) show that this finding is consistent when weather conditions are taken into account and when locked-down cities and unlocked-down cities in 2020 are compared. ${ }^{6}$

\subsection{Spillover Effects}

Although the lockdown policy issued by the Wuhan government was only effective in Wuhan city, it had repercussions across China. People began to realize the seriousness of COVID-19, and modified their social behaviors. Many people outside Wuhan also tried to spend less time outdoors to reduce the risk of exposure to the virus. Factories and corporations began to reduce their physical interaction with firms or people from Wuhan. All of these behavioral shifts changed local economic and social life, and in turn affected air pollution.

To investigate the spillover effects of the Wuhan lockdown, we include a dummy variable PostWuhan, which takes the value of 1 after Wuhan city issued its lockdown policy,

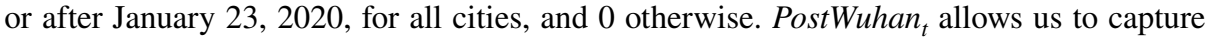
the change in air pollution induced by the Wuhan lockdown outside Wuhan. Specifically, we re-estimate the impact of lockdown policies on air pollution using the following DID specification:

$$
\ln (A Q I)_{i, t}=\alpha_{i}+\beta_{2} \text { Treat }_{i, t} * \text { Post }_{i, t}+\beta_{2} \text { Treat }_{i, t} * \text { PostWuhan }_{i}+W_{i, t}+X_{i, t}+\epsilon_{i, t}
$$

where $i$ denotes the city and $t$ denotes the day. The key variables here are Treat $_{i, t} *$ Post $_{i, t}$ and Treat $_{i, t} *$ PostWuhan $_{i}$, which captures the impact of each city's lockdown policies and the spillover effect of the Wuhan lockdown policy. Table 5 reports the regression results.

Column (1) and (2) compares the locked-down cities in 2020 to the same cities in 2019 and the locked-down cities to unlocked-down cities in 2020, respectively. For robustness, we also compare the unlocked-down cities in 2020 to the same cities in 2019 in column (3). The coefficients of Treat $*$ Post are consistent with previous results. These coefficients are significantly negative in all columns, although they are slightly smaller than the coefficients of Treat * Post in magnitude. Furthermore, column (3) estimates the impact of the Wuhan lockdown policy on cities without any official lockdown policy in 2020 and suggests that those cities also had lower air pollution in 2020 after Wuhan was locked down. These results suggest that the Wuhan lockdown had a significant spillover effect on other cities. $^{7}$

\footnotetext{
${ }^{6}$ As the anticipatory effect is an expected behavioral effect of trying to move out before quaranteen is imposed, it should be largely related to public traffic. To further explore this mechanism, we thus conduct further tests by adding an interaction of Treat $*$ Before with variable Traffic, which captures the public traffic or the total number of high-speed rails in each city, into model (4). The results present that the coefficients of interaction are significantly positive, which provide further evidence of the anticipatory effect. Due to the limitation of space, we do not present the details but related results are available upon request.

${ }^{7}$ One concern is that this spillover effect could be totally explained by the spillovers a perception of health risk rather than future lockdown policies. To further distinguish these two channels, we thus conduct further tests by adding an interaction of Treat $*$ PostWuhan with variable Distance, which captures the real distance to Wuhan of each city, into model (5). The results present that the coefficients of interaction are significantly positive and the coefficients of Treat $*$ PostWuhan are still significantly negative, suggesting that after eliminating this concern of health risk perception, our findings remain robust. Due to the limitation of space, we do not present the details but related results are available upon request.
} 
Table 5 Spillover effects

\begin{tabular}{llll}
\hline Treatment group & AQI & & \\
\cline { 2 - 3 } & Locked cities 2020 & Locked cities 2020 & Normal cities 2020 \\
Control group & Locked cities 2019 & Unlocked cities 2020 & Normal cities 2019 \\
& $(1)$ & $(2)$ & $(3)$ \\
\hline Treat * Post & $-0.127 * * *$ & $-0.083^{* * * *}$ & - \\
& $(0.023)$ & $(0.020)$ & - \\
Treat * PostWuhan & $-0.054^{* *}$ & $-0.038^{*}$ & $-0.114^{* * *}$ \\
& $(0.023)$ & $(0.020)$ & $(0.010)$ \\
Weather & Yes & Yes & Yes \\
Fixed effects & Yes & Yes & Yes \\
Constant & $3.880^{* * *}$ & $3.846^{* * *}$ & $3.906^{* * *}$ \\
& $(0.036)$ & $(0.024)$ & $(0.018)$ \\
Observations & 6602 & 13,858 & 20,996 \\
$\mathrm{R}^{2}$ & 0.528 & 0.580 & 0.576 \\
\hline
\end{tabular}

This table reports the spillover effect of the lockdown policy. Column (1) compares the locked cities in 2020 to itself in 2019, column (2) compares the locked cities in 2020 to unlocked cities in 2020, and column (3) compares the unlocked cities in 2020 to itself in 2019. All columns present the regression with both the weather conditions and fixed effects. The dependent variable is $A Q I$. The key independent variable is Treat $*$ PostWuhan. Significance at $10 \%, 5 \%$, and $1 \%$ levels was indicated by *,**, and ***, respectively

\subsection{Connections with Wuhan}

In this section, we investigate how cities' connections with Wuhan affect our findings. As a key element of virus propagation and the target of lockdown policies, the route of transmission considerably impacts people's risk of exposure to COVID-19. It would also distort the behaviors of people and governments by increasing public panic, and encouraging people to escape from dangerous cities, promoting government intervention. Thus, it should also affect the relationship between lockdown policies and air pollution.

We examine this by adding the variable Connections to capture the effect of connections to Wuhan. We collect between-city population movements data during January 1 to 15, 2020, from the Baidu Migration data. The Baidu Migration data are based on realtime location records for every smart phone that uses the Baidu Map app or other apps imbedding the Baidu Map Software Development Kit. Baidu currently dominates the search engine market in China for both desktop computers and especially mobile phones (accounting for $79.63 \%$ of the mobile phone market in May 2019). ${ }^{8}$ Thus, Baidu's migration data can precisely reflect population movements. We choose the daily In-Migration Index of Wuhan city, which is the percentage of population inflow from a corresponding

${ }^{8}$ https://www.marketmechina.com/baidu-search-engine-market-share-in-china-may-2019. 
Table 6 Connections with Wuhan

\begin{tabular}{|c|c|c|c|c|}
\hline \multirow{4}{*}{$\begin{array}{l}\text { Treatment group } \\
\text { Control group }\end{array}$} & \multicolumn{4}{|l|}{ AQI } \\
\hline & \multicolumn{2}{|c|}{ Limited cities 2020} & \multicolumn{2}{|c|}{ Limited cities 2020} \\
\hline & \multicolumn{2}{|c|}{ Limited cities 2019} & \multicolumn{2}{|c|}{ Normal cities 2020} \\
\hline & (1) & (2) & (3) & (4) \\
\hline \multirow[t]{2}{*}{ Treat $*$ Post } & $-0.056^{*}$ & $-0.092 * * *$ & -0.036 & $-0.054^{*}$ \\
\hline & $(0.030)$ & $(0.029)$ & $(0.030)$ & $(0.028)$ \\
\hline \multirow[t]{2}{*}{ Connections * Treat $*$ Post } & $-0.105 * * *$ & $-0.088 * * *$ & $-0.063^{*}$ & $-0.071^{* *}$ \\
\hline & $(0.031)$ & $(0.029)$ & $(0.034)$ & $(0.032)$ \\
\hline Weather & No & Yes & No & Yes \\
\hline Fixed effects & Yes & Yes & Yes & Yes \\
\hline \multirow[t]{2}{*}{ Constant } & $4.252 * * *$ & $3.869 * * *$ & $4.118 * * *$ & $3.843 * * *$ \\
\hline & $(0.007)$ & $(0.035)$ & $(0.004)$ & $(0.024)$ \\
\hline Observations & 6602 & 6602 & 13,860 & 13,858 \\
\hline $\mathrm{R}^{2}$ & 0.454 & 0.528 & 0.525 & 0.580 \\
\hline
\end{tabular}

This table reports the impact of connections with Wuhan on the effect of lockdown policy. Column (1) and (2) compare the locked cities in 2020 to itself in 2019, and column (3) and (4) compare the locked cities in 2020 to unlocked cities in 2020. Besides, column (1) and (3) present the result with the fixed effects, and column (2) and (4) present the regression with both the weather conditions and fixed effects. The dependent variable is $A Q I$. The key independent variable is Connections $*$ Treat $*$ Post

Significance at $10 \%, 5 \%$, and $1 \%$ levels was indicated by $* * *$, and $* * *$, respectively

city into Wuhan relative to the total population inflow for Wuhan, and calculate the average In-Migration Index of each city to Wuhan. Next, we define Connections as a dummy variable takes the value of 1 if population inflow from city $i$ to Wuhan is larger than average, and 0 otherwise, and then estimate the following model:

$$
\ln (A Q I)_{i, t}=\alpha_{i}+\beta_{2} \text { Treat }_{i, t} * \text { Post }_{i, t}+\beta_{2} \text { Connections }_{i} * \text { Treat }_{i, t} * \text { Post }_{i}+W_{i, t}+X_{i, t}+\epsilon_{i, t}
$$

where $i$ denotes the city and $t$ denotes the day. The key variable of our DID design here is Connections $_{i} *$ Treat $_{i, t} *$ Post $_{i, t}$, which captures the impact of a city's connection to Wuhan and how this connection affect the effect of lockdown. Table 6 reports the regression results.

The coefficient of Connections $*$ Treat $*$ Post in column (1) is significantly negative, which suggests that air pollution decreased more in cities that had more connections with Wuhan. Columns (2) to (4) show that the impact of connections is consistent when weather conditions are taken into account or when locked-down cities are compared to unlocked-down cities in 2020. Note that the coefficient of Treat*Post in column (3) is insignificantly different from zero. However, when we include weather conditions in estimating the model in column (4), this coefficient becomes significantly negative again. All of these results demonstrate that connections with Wuhan significantly affected the effect of the lockdown policy. 


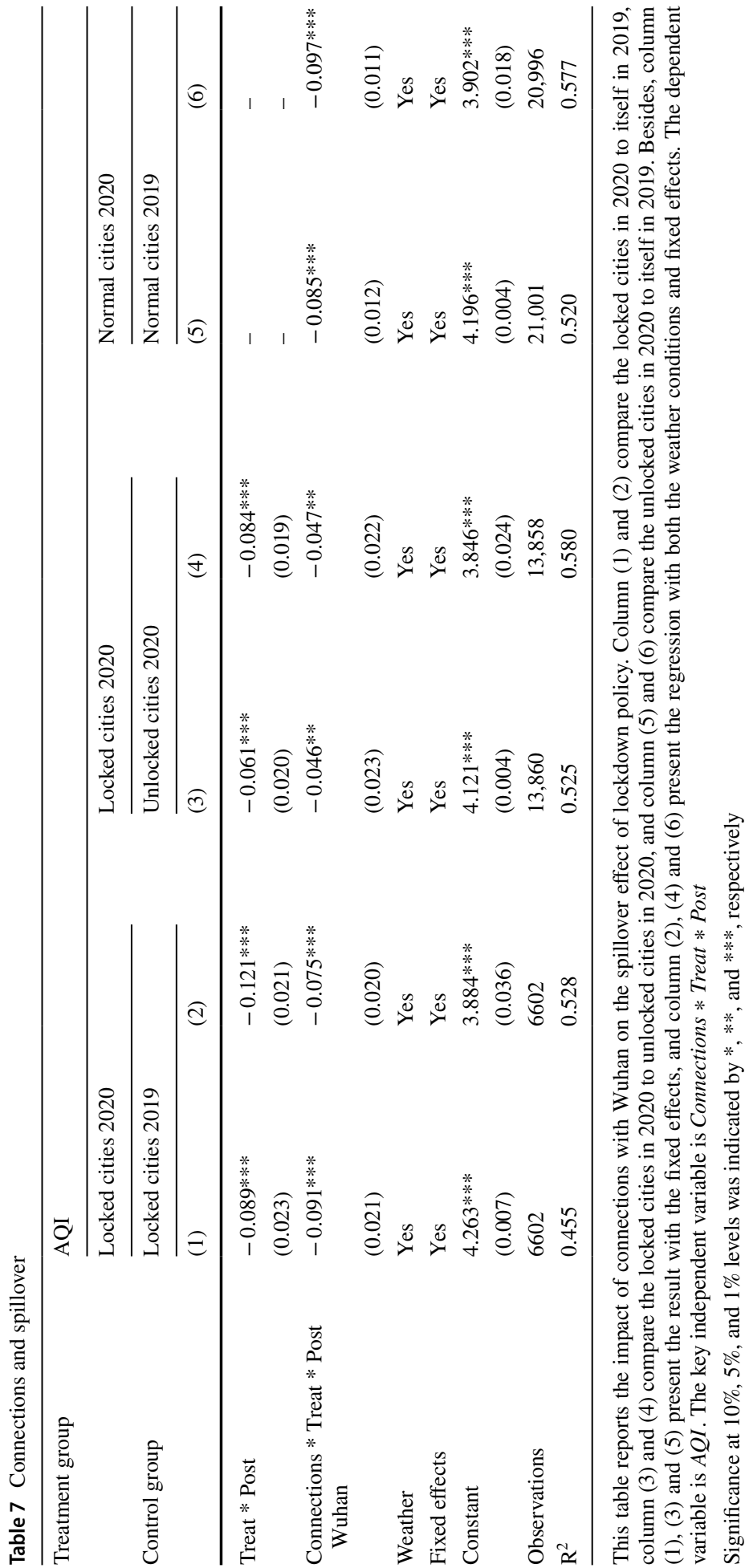


Table 8 Heterogeneity

\begin{tabular}{|c|c|c|c|c|}
\hline \multirow{4}{*}{$\begin{array}{l}\text { Treatment group } \\
\text { Control group }\end{array}$} & \multicolumn{4}{|l|}{ AQI } \\
\hline & \multicolumn{2}{|c|}{ Locked cities 2020} & \multicolumn{2}{|c|}{ Locked cities 2020} \\
\hline & \multicolumn{2}{|c|}{ Locked cities 2019} & \multicolumn{2}{|c|}{ Unlocked cities 2020} \\
\hline & (1) & (2) & (3) & (4) \\
\hline \multicolumn{5}{|l|}{ Panel A: self-isolation } \\
\hline Movements $*$ Treat $*$ Post & $\begin{array}{l}0.106 * * * \\
(0.019)\end{array}$ & $\begin{array}{l}0.103 * * * \\
(0.018)\end{array}$ & $\begin{array}{l}0.078 * * * \\
(0.021)\end{array}$ & $\begin{array}{l}0.086 * * * \\
(0.019)\end{array}$ \\
\hline Weather & No & Yes & No & Yes \\
\hline Fixed effects & Yes & Yes & Yes & Yes \\
\hline Observations & 6602 & 6602 & 13,860 & 13,858 \\
\hline $\mathrm{R}^{2}$ & 0.456 & 0.530 & 0.526 & 0.581 \\
\hline \multicolumn{5}{|l|}{ Panel B: anxiety } \\
\hline BaiduSearch*Treat*Post & $\begin{array}{l}-0.044 * * * \\
(0.015)\end{array}$ & $\begin{array}{l}-0.035^{* *} \\
(0.014)\end{array}$ & $\begin{array}{l}-0.046^{* * * *} \\
(0.017)\end{array}$ & $\begin{array}{l}-0.049 * * * \\
(0.016)\end{array}$ \\
\hline Weather & No & Yes & No & Yes \\
\hline Fixed effects & Yes & Yes & Yes & Yes \\
\hline Observations & 6602 & 6602 & 13,860 & 13,858 \\
\hline $\mathrm{R}^{2}$ & 0.435 & 0.494 & 0.492 & 0.547 \\
\hline \multicolumn{5}{|l|}{ Panel C: GDP incentive } \\
\hline GDP*Treat*Post & $\begin{array}{l}0.069 * * \\
(0.028)\end{array}$ & $\begin{array}{l}0.089 * * * \\
(0.026)\end{array}$ & $\begin{array}{l}0.014 \\
(0.033)\end{array}$ & $\begin{array}{l}0.055^{*} \\
(0.031)\end{array}$ \\
\hline Weather & No & Yes & No & Yes \\
\hline Fixed effects & Yes & Yes & Yes & Yes \\
\hline Observations & 6602 & 6602 & 13,860 & 13,858 \\
\hline $\mathrm{R}^{2}$ & 0.457 & 0.533 & 0.517 & 0.577 \\
\hline
\end{tabular}

This table reports the heterogeneity of the impact of lockdown policy. Column (1) and (2) compare the locked cities in 2020 to itself in 2019, and column (3) and (4) compare the locked cities in 2020 to unlocked cities in 2020. Besides, column (1) and (3) present the result with the fixed effects, and column (2) and (4) present the regression with both the weather conditions and fixed effects. The dependent variable is $A Q I$. The key independent variable in panel A, B, and $\mathrm{C}$ is Movements $*$ Treat $*$ Post, BaiduSearch $*$ Treat $*$ Post and GDP * Treat * Post, separately

Significance at $10 \%, 5 \%$, and $1 \%$ levels was indicated by $* * *$, and $* * *$, respectively

Next, we also investigate whether this kind of connection affects the spillover effect of the Wuhan lockdown. Specifically, we add Connection to Model (6). Table 7 reports the regression results.

The first, second, and last two columns of Table 7 compare the locked-down cities in 2020 to the same cities in 2019, locked-down cities to unlocked-down cities in 2020, and unlocked-down cities in 2020 to the same cities in 2019, respectively. We are interested in the coefficient of Connections $*$ Treat $*$ PostWuhan, which is significantly negative. These results suggest that connections with Wuhan also affected the spillover effect of the Wuhan lockdown. 


\subsection{Heterogeneity}

There is substantial heterogeneity in city characteristics across China which could have crucial implications for our findings. We now explore whether heterogeneity in citizens' willingness to self-isolate, public panic, or government GDP incentives might affect our main results.

First, we capture people's willingness to self-isolate by the daily Within-City Migration Index of Wuhan city Movements, which is the logarithm of the percentage of the population traveling outdoors to the total population living in the same city. Similar to the daily in-migration index, this index is based on Baidu Migration data. We interact this variable with Treat $*$ Post and include it in Model (1). Panel A of Table 8 reports the regression results.

Second, we capture public panic by Internet searches for COVID-19. Specifically, we collect the number of searches for COVID-19 from Baidu Index. First, Internet users commonly use a search engine to collect information, and Baidu continues to be the favorite in China, holding an $80 \%$ share of the Chinese search engine market. Second, and more critically, a search is a revealed private behavior. If someone searches for COVID-19, then he or she is undoubtedly feeling confused and threatened by it. Therefore, the aggregate search frequency is a good proxy for public panic. We define BaiduSearch as the logarithm of the search index and adjust it by the average search during the whole period within the corresponding city, and then interact it with Treat $*$ Post. Panel B of Table 8 reports the regression results.

Third, we capture governments' GDP incentive by comparing provincial-level GDP growth and the GDP growth target. Following Chen et al. (2020), we hand-collect the GDP data of each province from the websites of the Statistics Communiqué on National Economy, government reports, and the popular press. Then we define GDP as the difference between actual GDP growth in 2019 and the GDP growth target at the beginning of 2019, and interact it with Treat $*$ Post. Panel C of Table 8 reports the regression results.

The first two columns and second two columns of Table 8 compare the locked-down cities in 2020 to the same cities in 2019 and locked-down cities to unlocked-down cities in 2020, separately. Panel A shows that the coefficients of Movements*Treat*Post are significantly positive, suggesting that within-city population movements considerably decrease the impact of lockdown policies. This demonstrates that the effectiveness of lockdown policies is significantly reduced within cities where fewer people prefer self-isolation. Panel B shows that the coefficients of Baidu Search*Treat*Post are significantly negative, which suggests that public panic would stop people going outside. This in turn would significantly decrease air pollution induced by daily activities and transportation. This demonstrates that the effectiveness of lockdown policies would be significantly increased within cities with a greater sense of public panic. Panel C shows that the coefficients of GDP*Treat*Post are significantly positive, which suggests that governments that failed to achieve their economic target in the previous year are less effective when implementing lockdown policies.

In summary, we find that the effectiveness of lockdown policies is higher in cities that have more people willing to self-isolate, a greater sense of public panic, or a government facing less pressure to stimulate economic growth. 


\section{Conclusions}

The COVID-19 crisis was caused by a viral pandemic that abruptly and severely constricted human mobility and economic activity. To respond to the outbreak, governments worldwide have increasingly implemented strict public health measures, such as social distancing or even complete lockdown.

We contribute to the literature by examining the causal effects of COVID-19 on air quality in the Chinese context. Using the lockdowns of different cities as exogenous shocks, we conduct DID estimations and show that lockdown policies reduced air pollution in a statistically significant manner. We further present three underlying mechanisms driving our findings: anticipatory effects, spillover effects, and the connection with Wuhan. Lastly, our findings are more pronounced in cities that have more people willing to self-isolate, greater public panic, or governments that face less pressure to stimulate economic growth.

Overall, by evaluating the unintended consequences of the COVID-19 pandemic for air quality, this study provides timely policy implications for policymakers. In particular, our results indicate that policy makers should pay more attention to the fairness and timeliness of information disclosure to avoid the anticipatory effects, and take better into account the existing connections between cities, including economic, labor or cultural connections with other areas.

Acknowledgements We thank Katti Millock (the editor), Rui Shen, Haijian Zeng, and seminar participants at Huazhong University of Science and Technology, Wuhan University, and Zhongnan University of Economics and Law for helpful suggestions. We also gratefully acknowledge the financial support from National Natural Science Foundation of China (Grant Nos. 71802061, 71972088, 71772178).

\section{Compliance with Ethical Standards}

Conflict of interest The authors declare that they have no conflict of interest.

\section{References}

Baker SR, Bloom N, Davis SJ, Kost KJ, Sammon MC, Viratyosin T (2020) The unprecedented stock market impact of COVID-19. NBER Working Paper No. 26945

Barron M, Torero M (2017) Household electrification and indoor air pollution. J Environ Econ Manag 86:81-92

Bartik AW, Bertrand M, Cullen ZB, Glaeser EL, Luca M, Stanton CT (2020) How are small businesses adjusting to COVID-19?. NBER Working Paper No. 26989

Chen SY, Guo CS, Huang XF (2018) Air pollution, student health, and school absences. J Environ Econ Manag 92:465-497

Chen H, Qian W, Wen Q (2020) The impact of the COVID-19 pandemic on consumption: learning from high frequency transaction data. SSRN Working paper

Coibion O, Gorodnichenko Y, Weber M (2020) Labor markets during the COVID-19 crisis: a preliminary view. NBER Working Paper No. 27017

Ding W, Levine R, Lin C, Xie W (2020) Corporate immunity to the COVID-19 pandemic. SSRN Working paper

Dingel JI, Neiman B (2020) How many jobs can be done at home? NBER Working Pape No. 26948

Fang H, Wang L, Yang Y (2020) Human mobility restrictions and the spread of the novel coronavirus (2019-nCoV) in China. NBER Working Paper No. 26906

Freeman R, Liang WQ, Song R, Timmins C (2019) Willingness to pay for clean air in China. J Environ Econ Manag 94:188-216

Fu SH, Gu YZ (2017) Highway toll and air pollution: evidence from Chinese cities. J Environ Econ Manag 83:32-49 
Gelman A, Imbens G (2019) Why high-order polynomials should not be used in regressiondiscontinuity designs. J Bus Econ Stat 37:447-456

Hassan TA, Hollander S, van Lent L, Tahoun A (2020) Firm-level exposure to epidemic diseases: Covid-19, SARS, and H1N1. NBER Working Paper No. 26971

He G, Pan Y, Tanaka T (2020) COVID-19, city lockdown, and Air pollution: evidence from China. medR xiv:2020.2003.2029.20046649

Heyes A, Zhu MY (2019) Air pollution as a cause of sleeplessness. J Environ Econ Manag 98:102247

Jones AM, Harrison RM, Baker J (2010) The wind speed dependence of the concentrations of airborne particulate matter and NOx. Atmos Environ 44(13):1682-1690

Lalive R, Luechinger S, Schmutzler A (2018) Does expanding regional train service reduce air pollution? J Environ Econ Manag 92:744-764

Shi X, Xu Z (2018) Environmental regulation and firm exports. J Environ Econ Manag 89:187-200

Wang CH, Wu JJ, Zhang B (2018) Environmental regulation, emissions and productivity. J Environ Econ Manag 92:54-73

Zhang W, Lawell CYCL, Umanskaya VI (2017) The effects of license plate-based driving restrictions on air quality. J Environ Econ Manag 82:181-220

Publisher's Note Springer Nature remains neutral with regard to jurisdictional claims in published maps and institutional affiliations. 